\title{
A novel mutation of COL4A1 responsible of familial porencephaly and severe hypermetropia
}

\section{P. Scoppettuolo ${ }^{1}$, N. Ligot ${ }^{1}$, G. Naeije ${ }^{1}$, V. Wermenbol ${ }^{2}$, P. Van Bogaert ${ }^{3}$}

${ }^{1}$ Hôpital Erasme - ULB, Neurology, Brussels, Belgium.

${ }^{2}$ Hôpital Erasme - ULB, Neuropediatrics, Brussels, Belgium.

${ }^{3} \mathrm{CHU}$ Angers, Pediatrics, Angers, France.

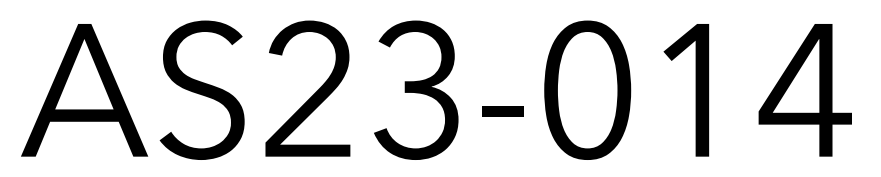

\section{Background and Aims}

COL4A1 is a gene responsible for a broad spectrum of syndromes characterized by small vessel involvement of variable severity, including neurological manifestations (porencephaly, aneurysms), ophthalmologic (retinal artery tortuosity and Axenfeld-Rieger anomaly), renal (renal cysts, microscopic hematuria) and systemic (cramps, Raynaud's phenomenon, arrhythmias).

\section{Method}

We studied a non-consanguineous family (image.1) with 3 cases of porecencephaly. IV-2 and IV-5 developed left and right hemiplegia respectively, had hypermetropia (8.50 and 15 dioptres (D)). IV-2 has epilepsy under valproic acid. IV-5 had mild psychomotor retardation and slight elevation of CK. IV-4 is hyperopic, microcephalic, with light mental retardation and the MRI shows a porencephalic cyst. The father had severe hypermetropia (7 D), bilateral cataract and nonspecific abnormalities of brain white matter. His mother suffered from lameness attributed to a forceps delivery: this has allowed suspecting an unknown hereditary pathology and a dominant inheritance. A genetic analysis reveals for father and three out five children a COL4A1 mutation of the type (c.2228G> T [p.Gly743Val]), not reported previously.

\section{Results}

We discover a new autosomal dominant mutation of COL4A1. Glycine is chemically different, highly conserved and crucial for the formation of $\alpha 1 \alpha 1 \alpha 2$ heterotrimers of collagen IV. The systemic balance shows cerebral and ocular involvement.
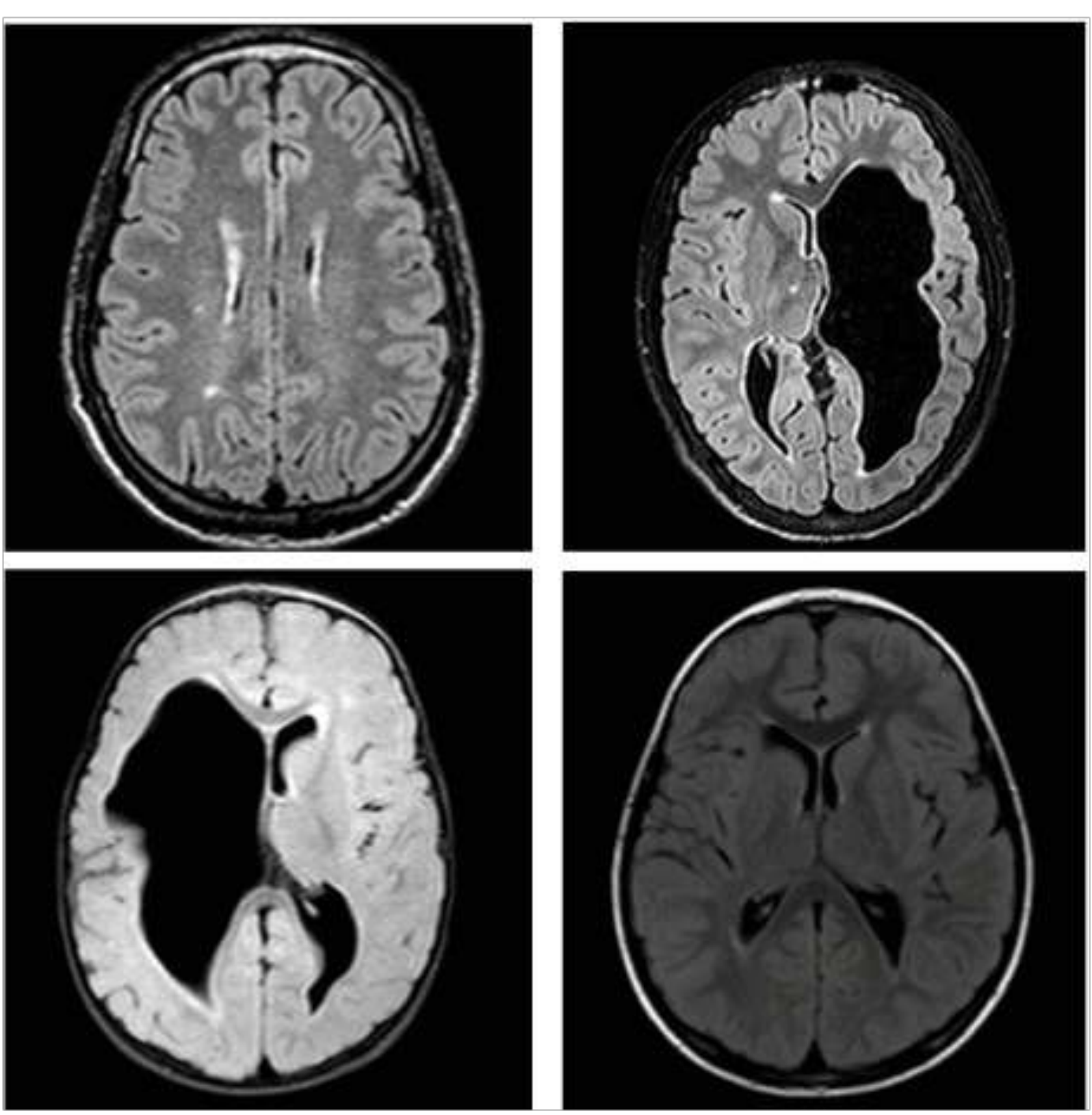

II

III

IV

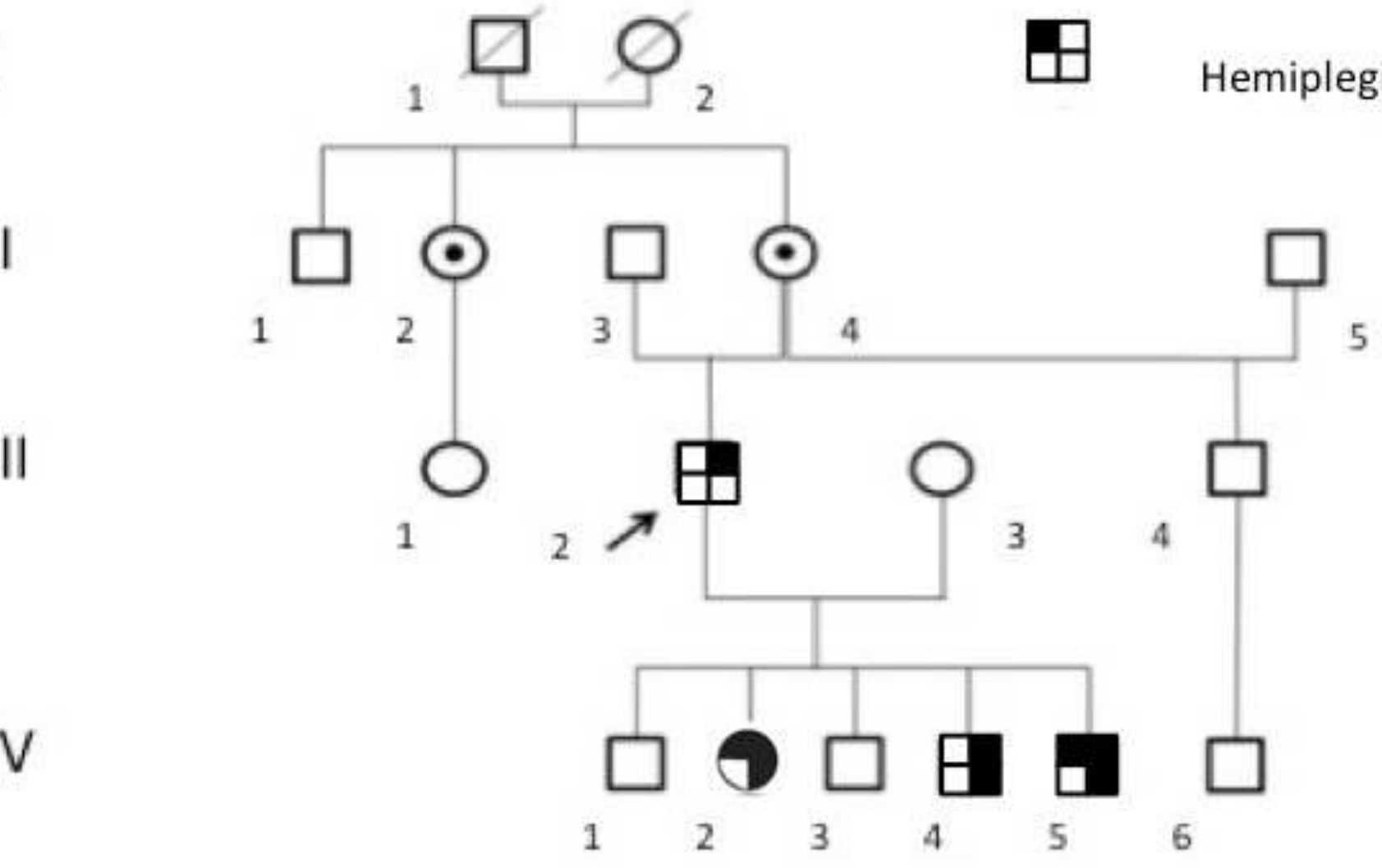

Image 1: Pedigree

\section{Conclusion}

A mutation of the COL4A1 gene must be suspected in case of congenital porencephaly, early white matter abnormalities, ocular and renal involvement with familial history suggesting autosomal dominant inheritance with incomplete penetrance. For asymptomatic patients biannual monitoring of renal function, cerebral and vessel imaging and ophthalmologic follow-up are indicated.

Image 2: MRI from III-2, IV-2, IV-5, IV-4 respectively

\section{References:}

